\title{
Development and Application of Online Courseware for English Teaching
}

\author{
$\underline{\text { http://dx.doi.org/10.3991/ijet.v11i03.5197 }}$ \\ Shansong Huang \\ University of Science and Technology Liaoning, Anshan, China
}

\begin{abstract}
Since the second decade of the 21st century, the rapid development of computer information technology promoted the internet use throughout society. We are now in an era in which life and learning are closely intertwined with the internet. In Western Europe, the United States, and other developed countries, teaching activities by online multimedia and offline technology have been long implemented. However, local online automatic generation software is inflicted with many issues, particularly, with the inability to meet the most student needs. Hence, we developed a new online courseware generation system to address this problem. After testing, the system functioned effectively, and the educational effect enhanced significantly.
\end{abstract}

Index Terms—online courseware, modularity, English teaching

\section{INTRODUCTION}

Since the second decade of the 21 st century, the rapid development of computer information technology promoted the use of the internet throughout the world. This period began an era in which life and learning could no longer be separated from the internet. At present, enterprises, government departments, state-run institutions such as schools, or any other establishments that can create and maintain a full database could share intellectual properties. This sharing of information is considered to be one great benefit of the internet era learning [1]. However, online multimedia teaching has so far failed to fully maximize this opportunity. The creation and research on online courseware generation remain focused on simple technical processes, such as database accumulation and storage. The most common online teaching system is used for educational resources, such as audio and video images, text documents, and exam databases. This system does not integrate training resources sufficiently to deal with the various needs of different students [2]. Additionally, traditional online multimedia teaching courseware does not update automatically. Hence, students cannot learn effectively through this platform, especially at the end of the semester or as they commence their use of the online courseware. Thus, students often cease using the online teaching and the active exit online learning systems because of unstimulating learning and arduous requirements, respectively [3]. Therefore, the research and development of automatic generation models and systems of college and university online multimedia teaching courseware is a meaningful concern for learning institutions.

In the recent years, domestic scholars and institutions of relevant educational areas have committed to the research and reform of online courseware automatic generation systems. Exploration in this area continues to date. Experts from colleges and universities had been increasingly dedicated to research in this field in the recent years. They contributed many initial theoretical and practical insights into the topic. For the development and application of online courseware generation systems in educational teaching, foreign research commenced earlier than local exploration. Foreign research presented a variety of trends and formed a relatively complete system of education and teaching. These researchers attempted to integrate some social network applications that include MySpace, Facebook, and Wikipedia, as well as blogs with online teaching lessons in order to meet the needs of the students of 21 st century [4]. In local efforts, the basic structure of a considerable part of the education and training institutions' courseware production systems was consistent with almost all of the major software vendors, such as PowerPoint (PPT) [5] and Flash [6]. This type of software uses the page editing mode during the production of online courseware, which allows its own independence. However, the timing and format of the courseware is highly inconvenient [7]. The major drawbacks of such software is it's lengthy courseware period. It consumes excessive time from the students to study, the inconsistent levels of difficulty, and the slower learning progress of new students. Consequently, the efficiency of use of this type of online courseware is low.

At present, two kinds of automatic generation of software are primarily available in the market. The first kind corresponds to the main teaching content of the online courseware considered with specific structure, and the basic format and module of the content of the courseware was fixed. To prevent leakage or illegal use of teaching resources, the system does not allow automatic expansion. In this case, teaching modifications to the courseware content and teaching style are forbidden, making the system not conducive to instruction. This kind of online courseware development software is not only difficult to adapt by the students' individual levels but also could not be personalized to teach students based on their aptitudes. As a result, the software could not cover the different stages of educational targets. To address these issues, the experts who are familiar with another kind of courseware development system explored this system by open resource. Particularly, these experts developed the online courseware generation system by themselves. This strategy may be effective but also generated other problems. For example, the courseware designer could not meet actual needs of the students because of his/her ignorance of each teacher's teaching level, teaching tasks, and teaching styles.

The advantage of our design lies in our intent to address the above-mentioned issues of the traditional courseware 
system that includes the restriction of adding and deleting resources, lack of standardization, and low flexibility. This design uses XML and HTML standard formats to generate their own system of courseware template. The systems in the database can be updated regularly, which is favorable for users at different stages. To evaluate the effectiveness of this online system, we apply this system to a College English class in the form of a teaching experiment. Through this process, we aim to obtain teaching ideas and reference for further teaching development.

\section{THEORETICAL BASIS AND RELATED TECHNOLOGY}

\section{A. Online courseware development technology}

CSS+DIV were used in accordance with world website design standards ("WEB standard"). CSS+DIV is the most commonly used in the web layout, but it is dissimilar to HTML tags. This format can be adopted to generate web page content, and its component performances do not interfere with each other. In this paper, the overall page design and online courseware development mainly used CSS+DIV technology. This technology holds several advantages for the web layout as follows:

1. Unnecessary codes were deleted.

2. From the technical aspect, XHTML is not required to be nested in the form of a web page.

3. The online courseware data are modularized, which not only simplifies the website revision procedures but also saves considerable costs.

In addition, the auxiliary design utilizes XML language [8], which provides the following three advantages: 1 . the standardization of courseware content, 2. open courseware with the powerful retrieval ability of XML, and 3 . organization of courseware information.

\section{B. Development process of online courseware}

The online courseware design uses Apache as the web server, and MySQL5.6 as back-end database, that also supports HTML5 and CSS3 techniques. In this design, we first compose split and suitable courseware information and teaching information by time duration. Then, we allow resource deletions and additions to the courseware. We also categorize teaching information by type of information and then modularized these data. Finally, we designate a predetermined time as a unit, and we add the split courseware information and teaching information into the course database by time duration to form the final database storage. The technical styles adopted in generating the online courseware are listed in Figure 1.

The structure of the automatically generated online courseware should meet the needs of actual teaching and allow diversification. In the design structure, all courseware must strictly follow standard operation. All courseware should include a standard format to ensure the combination compatibility of courseware modules. In the interim, all modules are permitted to adopt their own characteristics (i.e., degree of difficulty and style).

\section{Development principles of the online courseware}

Given the analysis of the above-mentioned aspects, we should consider following points in the development and production of online courseware:

The courseware should be accessible. The purpose of the courseware is to improve the class teaching content and enhance the efficiency of classroom teaching. Courseware development is not only beneficial for teachers' teaching, but also for students' learning. This system classifies teaching information into related database modules by the different times they consume to learn.

The courseware should be easy to use. The limited time of online learning suggests that the courses must be simple and readily applicable.

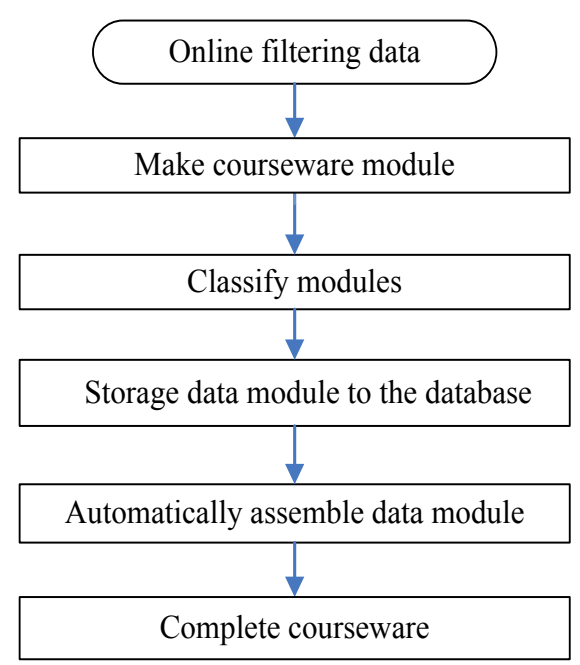

Figure 1. Technology of the online courseware automatic generation system

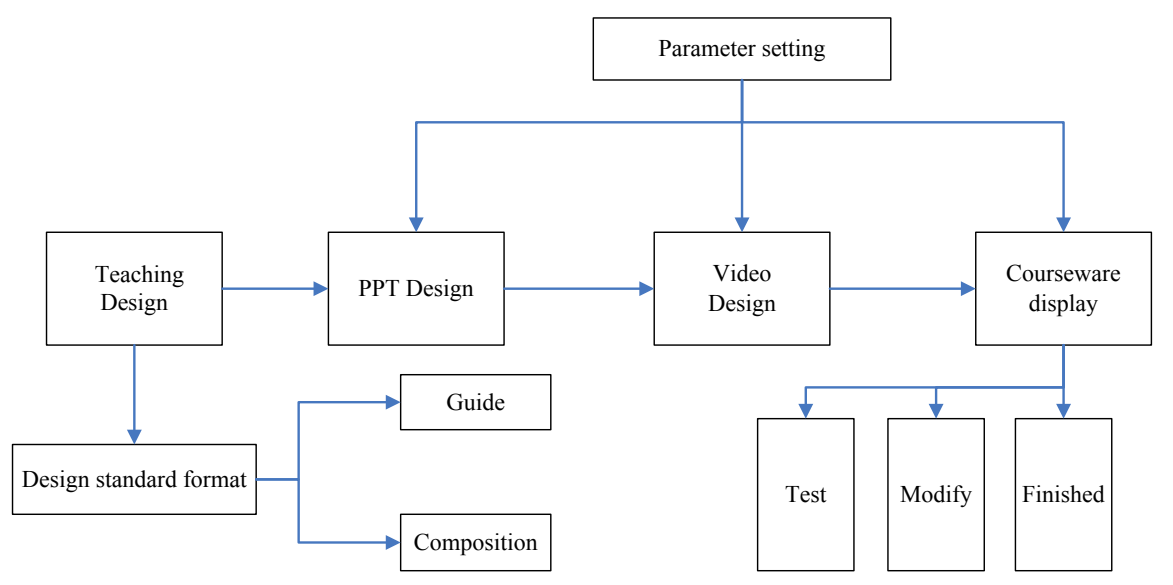

Figure 2. Schematics of the online courseware automatic generation system 


\section{REALIZATION OF ONLINE COURSEWARE DEVELOPMENT}

We then apply the technical design and construct a web page to conduct a system test run. As shown in Figure 3, not all users can log in. Users can only enter the interface of online courseware generation upon payment of a prescribed fee.

Based on the information demands, the users were provided in the previous phase, the system will assemble the relevant courseware in the existing database to mobilize and optimize integration by chronological order. In Figure 5, we choose PPT from the courseware types and designed an online courseware in the chosen courseware module. We then select medium difficulty to suit personal need. Finally, the system assembles the module resources from the existing database for integration and forming the online courseware interface that is shown in Figure 5.

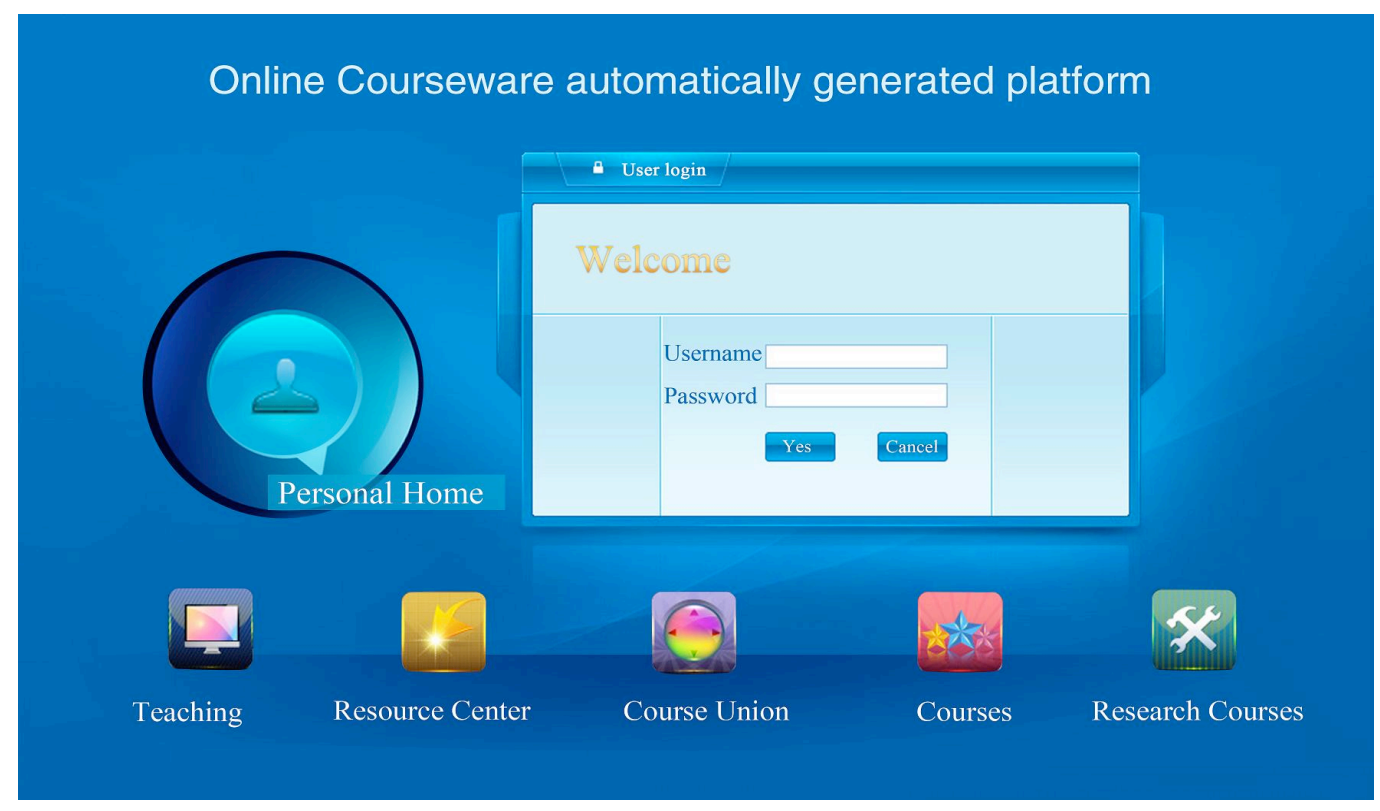

Figure 3. Online courseware platforms

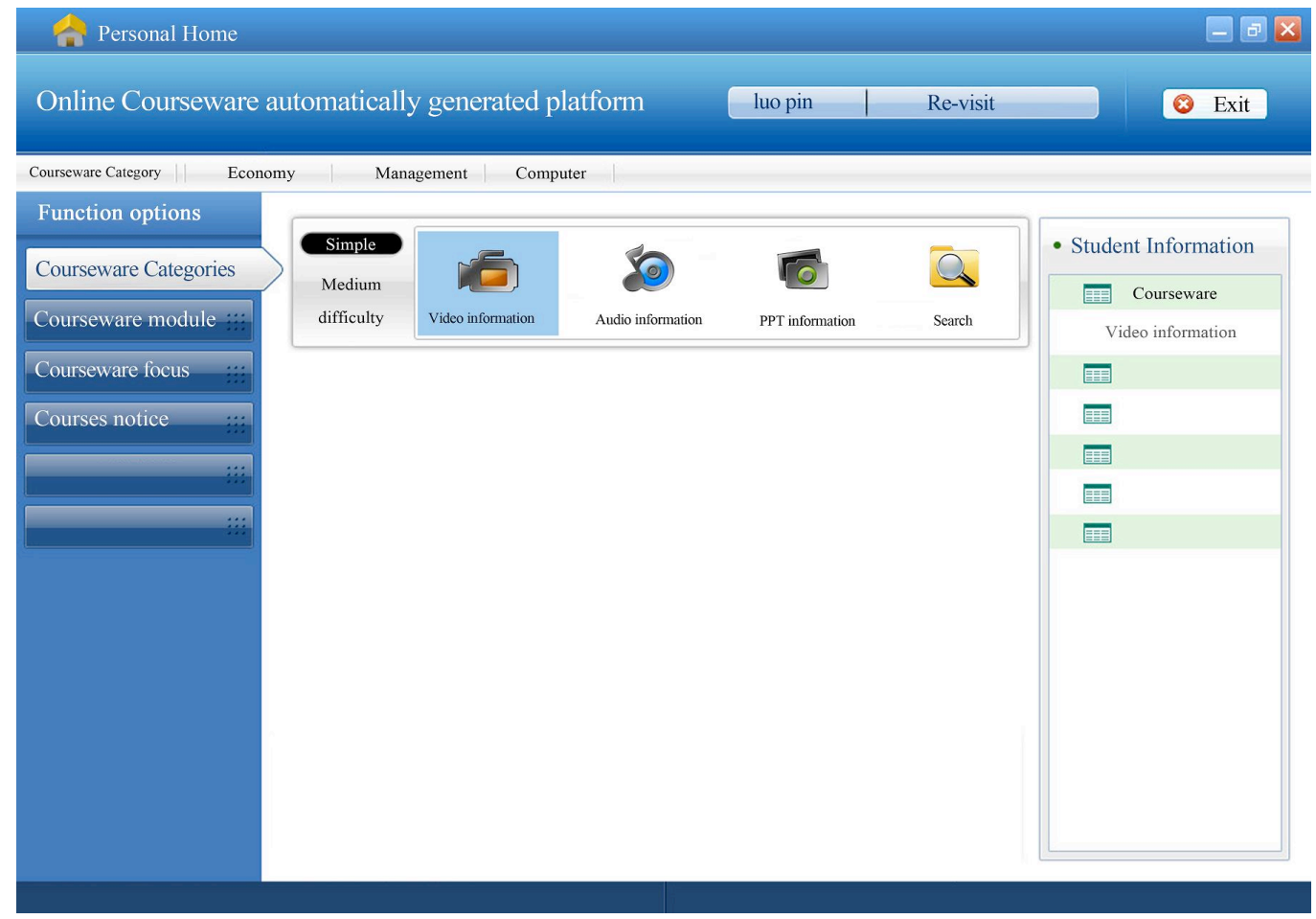

Figure 4. Selection interface of the online courseware 


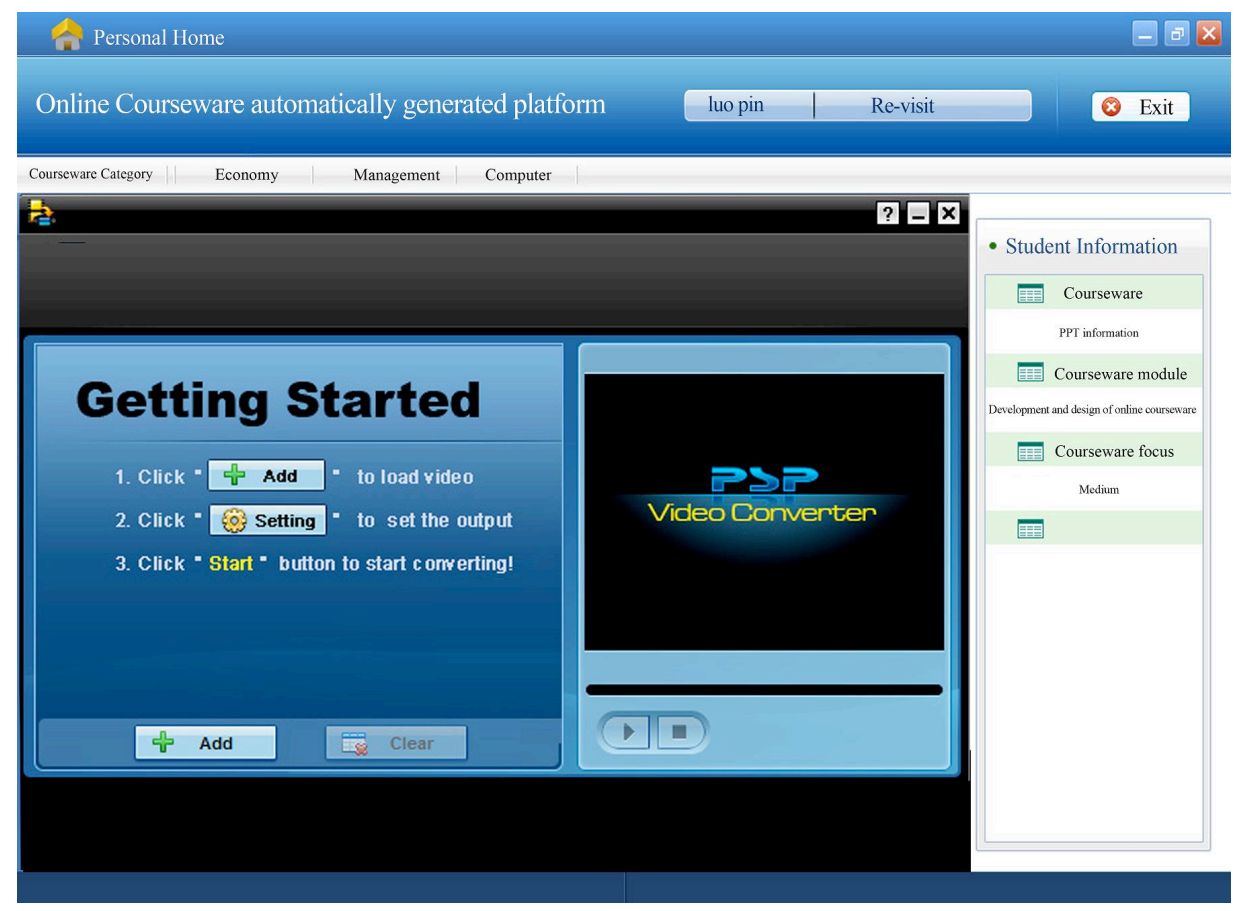

Figure 5. Final interface of the online courseware

\section{Application Of The OnLine COURSEWARE AUTOMATIC GENERATION SOFTWARE IN ENGLISH TEACHING}

\section{A. Experimental objects}

Freshman Chinese University students are selected randomly and enrolled in the experimental course "College English." A total of 100 students (50 males and 50 females) were selected. The first 50 students were enrolled in classes 1 to 4 and designated as the experimental group. The remaining 50 students were enrolled in classes 5 to 8 and designated as the control group. The students in the experimental group use the online courseware system designed in this paper. The control group uses regular teaching software for English learning. The learning content and requirements as well as the arrangement of the semester hours (one semester of 56 h) were the same for the two groups of students.

\section{B. Evaluation of learning}

In this paper, we summarize the vocabulary, writing, reading, and total scores of all the research subjects. After calculating the standard, we tested whether the two kinds of different online teaching software significantly affect the performance of the two classes. In addition, we evaluated the effect of English learning through the system platform by a previously developed questionnaire on the slackness of the teenagers' learning [9]. This questionnaire was compiled by Dai et al. [9]. It contains 16 entries and addresses three factors: physical and mental exhaustion, academic alienation, and low sense of achievement. The questionnaire utilizes the Likert fivepoint scale, in which 1 represents very inconsistent and the 5 represents very consistent. In this paper, the scores for the above-mentioned factors were determined to be $0.69,0.76$, and 0.82 , respectively [9].

\section{Statistical methods}

The results were analyzed using SPSS 11.5 statistical software. The quantitative data were expressed by as means \pm standard deviations. The comparison between the two groups was inspected by t-test. Differences at $\mathrm{P}<$ 0.05 between groups were considered statistically significant.

\section{Experiential results}

After completing a semester of lessons, the scores of the experimental group in listening, reading, writing, and vocabulary, as well as the total scores, were significantly higher than those of the control group $(\mathrm{P}<0.001)$.

In terms of slackness of student's learning, the experimental group obtained significantly lower scores in physical and mental exhaustion, academic alienation, and low sense of achievement compared with those of the control group $(\mathrm{P}<0.001)$.

TABLE I.

COMPARISON OF TEST RESULTS ON ENGLISH BASIC LEARNING

\begin{tabular}{cccccc}
\hline Group & listening & reading & writing & vocabulary & total scores \\
\hline Contrast group & $79 \pm 6$ & $78 \pm 6$ & $69 \pm 5$ & $67 \pm 5$ & $73 \pm 7$ \\
Experimental group & $85 \pm 7$ & $83 \pm 6$ & $76 \pm 5$ & $74 \pm 6$ & 6.338 \\
$\boldsymbol{t}$ & 4.602 & 4.167 & 7.000 & $<.602$ \\
$\boldsymbol{P}$ & $<0.001$ & $<0.001$ & $<0.001$ & $<0.001$ \\
\hline
\end{tabular}


PAPER

DEVELOPMENT AND APPLICATION OF ONLINE COURSEWARE FOR ENGLISH TEACHING

TABLE II.

COMPARISON OF SLACKNESS IN LEARNING

\begin{tabular}{cccc}
\hline Group & Physical and mental exhaustion & academic alienation & low sense of achievement \\
\hline Contrast group & $12.1 \pm 3.7$ & $11.4 \pm 3.1$ & $22.2 \pm 5.1$ \\
Experimental group & $10.5 \pm 4.1$ & $10.0 \pm 3.5$ & $20.1 \pm 5.2$ \\
\hline $\boldsymbol{t}$ & 2.049 & 2.117 & 2.039 \\
$\boldsymbol{P}$ & 0.043 & 0.037 & 0.044 \\
\hline
\end{tabular}

The test performance of every unit shows that the students who used the online courseware generation system attained higher scores in all units than the control. This finding may be primarily due to more substantial content and faster updates in the online courseware generation system platform than those of the traditional one. Moreover, the module design of the courseware generation system is appropriate and varies in levels of teaching content that fit the different student demands. The major feature of the online courseware is the rich expression forms and interactive functions of various carriers. Through the comprehensive use of various media, a vivid and interesting teaching situation with updatable teaching content can be created. These lessons can integrate with knowledge resources from Baidu and Google, such as videos and foreign movies. These different teaching approaches can help students understanding the vocabulary at different locations and master language usage in actual linguistic situations.

In the experiment, the students used three modes of online courseware generation: the PPT, video, and audio teaching modes. The majority of the students held a positive and welcome attitude to the teaching results. This mode is also popular among many non-English majors. Student participation is high and the class atmosphere is stimulating. The survey on student slackness revealed that the slackness level of those who used the new system is apparently lower than that of the control group. This result may be explained by several reasons. Firstly, the timely update of the online courseware and the creation of teaching situations could have increased the students' learning interests. Secondly, the system enriched the multi-media teaching content and increased teaching information. Thirdly, the interactive function between the online website and multi-media was exploited to improve listening and speaking qualities. Fourthly, the multi-media technology used in the online courseware widened the students' insights and lowered the students' learning slackness that consequently improved their learning interests and academic performances.

\section{CONCLUSIONS}

After reading and analyzing numerous studies, we presented a detailed analysis and investigation of online courseware generation. We also discussed the necessary conditions for the construction of an online courseware automatic generation system. In this paper, we analyzed the development of suitable online courseware, determined the elements of quality online courses, and proposed a design plan for the construction of an online course automatic generation system.

Based on previously developed software, we designed and implemented the online courseware automatic generation system. The overall system structure and teaching template were developed and applied. Through testing, we verified the effectiveness of online courseware automatic generation system. No major errors and defects were found. The courseware interface is aesthetically appealing and rich in content with excellent dynamic effect that enables students to study independently.

\section{REFERENCES}

[1] Zeng R., Zhang Y., "Internet information overload on the impact of network learning," Distance education in China, vol. 26, no. 11, pp.16-18, November 2002.

[2] Goodyear P., Salmon G., Spector J.M., et al., "Competences for online teaching: A special report," Educational Technology Research and Development, vol. 49, no 1, pp.65-72, March 2001. http://dx.doi.org/10.1007/BF02504508

[3] Kim K., Bonk C.J., "The future of online teaching and learning in higher education: The survey says," Educause quarterly, vol. 29, no. 4, pp.22, January 2006.

[4] Deters F., Cuthrell K., Stapleton J., "Why Wikis? Student Perceptions of Using Wikis in Online Coursework," Journal of Online Learning and Teaching, vol. 6, no. 1, pp.122-134, March 2011.

[5] Fisher D.L., "Using PowerPoint for ESL teaching," The Internet TESL Journal, vol. 9, no. 4, pp.4, April 2003.

[6] Byun S., "Transaction Management for Flash Media Databases in Portable Computing Environments." Journal of Intelligent Information Systems, vol. 30, no. 2, pp.137-151, February 2008. http://dx.doi.org/10.1007/s10844-006-0022-z

[7] Clark J., "PowerPoint and pedagogy: Maintaining student interest in university lectures," College teaching, vol. 56, no. 1, pp.39-44, January 2008. http://dx.doi.org/10.3200/CTCH.56.1.39-46

[8] Ghaleb F., Daoud S., Hasna A., et al., "E-learning model based on semantic web technology," International Journal of Computing \& Information Sciences, vol. 4, no. 2, pp.63-71, August 2006.

[9] Dai X.Y., Wu Y., Wen Z.L., et al., "Compiling of youth learning slackness scale," Chinese Journal of Clinical Psychology, vol. 18, no. 2, pp.152-154, February 2010.

\section{AUTHOR}

Shansong Huang (Corresponding author) is a Lecturer in University of Science and Technology Liaoning, Anshan, 114051 China. Her research interests include English learning and online education (e-mail: hshansong@yeah.net)

Submitted 06 November 2015. Published as resubmitted by the author 25 February 2016. 